\title{
Repeatability of methacholine challenge in asthmatic children measured by change in transcutaneous oxygen tension
}

\author{
Stephen B Phagoo, Nicola M Wilson, Michael Silverman
}

\begin{abstract}
Background The airway response to bronchial provocation may be evaluated by monitoring the fall in transcutaneous oxygen tension $\left(\mathrm{PtcO}_{2}\right)$ but the repeatability of this method has not been rigorously assessed.

Methods To determine the repeatability of this indirect method of assessment, bronchial challenge was performed with methacholine in nine children with stable asthma (age range 6-12 years) and was repeated 24 hours later. The response was determined by the fall both in forced expiratory volume in one second $\left(F E V_{1}\right)$ and in $\mathrm{PtcO}_{2}$. A modified tidal inhalation protocol was used in which quadrupling concentrations of methacholine were given, thereby reducing the time taken for the full challenge by almost half. The concentrations of methacholine that provoked a $20 \%$ decrease in $\mathrm{FEV}_{1}$ $\left(P_{20} F_{E V}\right)$ and $15 \%$ and $10 \%$ falls in $\mathbf{P t c O}_{2}\left(\mathbf{P C}_{15} \mathbf{P t c O}_{2}, \mathbf{P C}_{10} \mathbf{P t c O}_{2}\right)$ were calculated.

Results Repeatability measures, assessed as the $95 \%$ range for a single determination, were \pm 0.96 and \pm 1.12 doubling concentration differences respectively for $\mathrm{PC}_{15} \mathrm{PtcO}_{2}$ and $\mathrm{PC}_{10} \mathrm{PtcO}_{2}$ and \pm 0.80 for $\mathrm{PC}_{20} \mathrm{FEV}_{1}$.

Conclusion This challenge method using quadrupling concentrations and an indirect assessment of the response by $\mathrm{PtcO}_{2}$ was sufficiently repeatable for clinical use and compared favourably with repeated challenge assessed by $\mathrm{FEV}_{1}$. The $\mathrm{PtCO}_{2}$ method is simple and effort independent, and should prove particularly useful for measuring bronchial reactivity in young children.
\end{abstract}

(Thorax 1992;47:804-808)

Department of Neonatal Medicine, Royal Postgraduate Medical School, Hammersmith Hospital, London W12 ONN $S$ B Phagoo NM Wilson M Silverman Reprint requests to: Dr S B Phagoo Received 25 October 1991 Returned to authors 19 December 1991 Revision received 21 February 1992 Accepted 19 March 1992 indirectly by monitoring the transcutaneous oxygen tension $\left(\mathrm{PtcO}_{2}\right){ }^{1-5}$ This method is not invasive, is effort independent, and has been successfully used with infants and preschool and older children. ${ }^{6-8}$ we have examined the repeatability of respon-
To investigate the reliability of the method, ses to methacholine challenge repeated within 24 hours. The repeatability with $\mathrm{PtcO}_{2}$ determination was compared with that with the forced expiratory volume in one second $\left(\mathrm{FEV}_{1}\right)$, which is widely accepted in clinical practice as a reliable method of assessing the response to bronchial challenge. The usual challenge procedures for methacholine are time consuming and tedious with uncooperative young children. Although abbreviated or rapid inhalation challenge protocols exist, ${ }^{910}$ the subject has to participate by inhaling the bronchoconstrictor stimulus during a timed inspiratory breath. We have modified the continuous tidal inhalation protocol, so reducing the time taken for the full challenge by almost half.

\section{Methods}

SUBJECTS

Twelve children with stable, well controlled asthma (age range 6-12 years) were selected from the children's asthma clinic. They were all capable of performing reproducible $\mathrm{FEV}_{1}$ manoeuvres after a short training period. Bronchodilator and sodium cromoglycate therapy were withheld for at least 12 hours before each challenge. Topical corticosteroid therapy was not interrupted. No subject had had a respiratory infection within the previous six weeks.

\section{CHALLENGE PROCEDURE}

The challenge test was carried out using a continuous inhalation tidal breathing method. ${ }^{11}$ Aerosols of methacholine chloride (Sigma Chemicals Ltd, Poole, Dorset) were delivered from a Wright nebuliser containing $5 \mathrm{ml}$ of solution producing a mean (SD) output of $0 \cdot 14(0.01) \mathrm{ml} / \mathrm{minute}$ using $8 \mathrm{l} / \mathrm{minute}$ of air as the driving gas. The methacholine solutions were made with $0.9 \%$ saline as the diluent and were renewed after each challenge. The same nebuliser was used throughout the study. A clip was placed on the nose and each aerosol was inhaled through a mouthpiece during quiet, tidal breathing for one minute. Methacholine was inhaled at five minute intervals firstly in concentrations that increased fourfold from $0.5 \mathrm{mg} / \mathrm{ml}$, and then in twofold increasing concentrations after the $\mathrm{PtcO}_{2}$ had fallen by approximately $1 \mathrm{kPa}$ from the mean baseline value. The challenge was continued until a $15 \%$ fall in $\mathrm{Ptco}_{2}$ had occurred or the maximum concentration of $16 \mathrm{mg} / \mathrm{ml}$ had been delivered. 
MEASUREMENT OF RESPONSE TO CHALLENGE

The response to challenge was monitored with a transcutaneous oxygen tension electrode (Model 820, Kontron Instruments Ltd, Switzerland) operating at $44^{\circ} \mathrm{C}$ and applied to the anterior chest wall. The electrode had previously been calibrated against air at room temperature, and was rechecked at the end of each study for drift (tolerance $\pm 0.1 \mathrm{kPa}$ ). Baseline values of $\mathrm{Ptco}_{2}$ were obtained at minute intervals for eight minutes after a $20-30$ minute equilibration period. After each challenge inhalation, $\mathrm{PtCO}_{2}$ values were recorded at minute intervals for three minutes immediately before the $\mathrm{FEV}_{1}$ measurement. The maximal fall in $\mathrm{PtcO}_{2}$ after each inhalation was used to construct a concentration-response curve.

The $\mathrm{FEV}_{1}$ was measured with a dry wedge spirometer (Vitalograph, Buckingham, UK). Before challenge, the highest value from three technically satisfactory attempts was accepted and the predicted $\mathrm{FEV}_{1}$ was calculated. ${ }^{12}$ After each challenge inhalation an $\mathrm{FEV}_{1}$ was measured at three minutes and repeated only if the first attempt was technically unsatisfactory. The $\mathrm{FEV}_{1}$ was recorded at three minutes since this timing was found to coincide with the maximal fall in $\mathrm{PtcO}_{2}$ after induced bronchoconstriction. The FEV ${ }_{1}$ manoeuvre was always performed after recording the $\mathrm{PtcO}_{2}$ since a maximal inspiration tends to increase transiently the $\mathrm{Ptco}_{2}$. The lowest $\mathrm{FEV}_{1}$ measured after each inhalation was used to construct a concentration-response curve. ${ }^{11}$

\section{STUDY DESIGN}

Each subject performed two identical methacholine challenge tests at the same time of day with a 24 hour interval. For each test, the baseline $\mathrm{FEV}_{1}$ was required to be more than $60 \%$ of a subject's predicted normal and within $\pm 10 \%$ of values on the previous test day.

The study was approved by the Ethics Committee of the Royal Postgraduate Medical School and informed consent was obtained from the parents of all subjects.

\section{EXPRESSION AND ANALYSIS OF DATA}

For each subject, the provocative concentrations of inhaled methacholine producing a $20 \%$ decrease in baseline $\mathrm{FEV}_{1}\left(\mathrm{PC}_{20} \mathrm{FEV}_{1}\right)$ and both a $15 \%$ and a $10 \%$ fall in baseline $\mathrm{PtcO}_{2}$
$\left(\mathrm{PC}_{15} \mathrm{Ptco}_{2}\right.$ and $\left.\mathrm{PC}_{10} \mathrm{Ptco}_{2}\right)$ were calculated from the $\log$ concentration-response curves by linear interpolation. Log transformed provocative concentration values were used in all analyses to obtain independence between within subject variability and the size of measurement.

Repeatability was assessed by examining the least squares linear regression of the provocative index obtained on the first and second study days. Student's paired $t$ test was used to determine whether the mean difference in provocative concentration between days was significantly different from zero. The means (SD) of the differences between the two values of $\mathrm{PC}_{20} \mathrm{FEV}_{1}, \mathrm{PC}_{15} \mathrm{Ptco}_{2}$, and $\mathrm{PC}_{10} \mathrm{Ptco}_{2}$ were determined and the within subject $\mathrm{SD}$ was calculated by dividing the SD of the differences by the square root of two. ${ }^{13}$ The $95 \%$ range for a single measurement for each provocative index was calculated from the formula:

$95 \%$ range $=t_{0.05} \times$ within subject SD.

The intraclass correlation coefficient, a dimensionless measure of repeatability, was calculated for each method by dividing the between subject variance by the total variance in a one way analysis of variance (ANOVA). ${ }^{14}$ Repeatability was also assessed according to the method of Bland and Altman. ${ }^{15}$

Differences in mean prechallenge $\mathrm{FEV}_{1}$ and $\mathrm{PtcO}_{2}$ for the two study days were assessed by Student's paired $t$ test. Changes in prechallenge $\mathrm{FEV}_{1}$ and $\mathrm{PtCO}_{2}$ were analysed for independence of $\mathrm{PC}_{20} \mathrm{FEV}_{1}$ and $\mathrm{PC} \mathrm{Ptco}_{2}$ values by means of the correlation coefficient.

\section{Results}

Nine subjects completed technically satisfactory studies. The results of three subjects were withdrawn because the starting concentration was too high in two and a $15 \%$ fall in $\mathrm{PtcO}_{2}$ was not achieved on either provocation day in one. In one subject on one day, the $\mathrm{PC}_{15} \mathrm{PtcO}_{2}$ was calculated by extrapolation of less than one doubling concentration. ${ }^{11}$

\section{BASELINE MEASUREMENTS}

Anthropometric and prechallenge pulmonary function and $\mathrm{PtcO}_{2}$ data are shown in table 1 . There was no significant difference in baseline $\mathrm{FEV}_{1}$ percentage of predicted value between

Table 1 Anthropometric data and baseline lung function

\begin{tabular}{|c|c|c|c|c|c|c|c|c|}
\hline \multirow{2}{*}{$\begin{array}{l}\text { Patient } \\
\text { No }\end{array}$} & \multirow{2}{*}{$\begin{array}{l}\text { Age } \\
(y)\end{array}$} & \multirow{2}{*}{$\begin{array}{l}\text { Height } \\
(\mathrm{cm})\end{array}$} & \multirow[b]{2}{*}{ Sex } & \multicolumn{2}{|c|}{ Baseline FEV (\% predicted) } & \multicolumn{2}{|c|}{ Baseline $\mathrm{PtcO}_{2}(\mathrm{kPa})$} & \multirow{2}{*}{$\begin{array}{l}\text { Coefficient of variation } \\
\left(\mathrm{PtcO}_{2}(\%)\right)\end{array}$} \\
\hline & & & & Day 1 & Day 2 & Day 1 & Day 2 & \\
\hline 1 & 7 & 129 & $\mathbf{M}$ & 102 & 97 & 8.9 & $12 \cdot 0$ & $1 \cdot 7$ \\
\hline 2 & 6 & 120 & $\mathbf{M}$ & 86 & 79 & $11 \cdot 2$ & $10 \cdot 6$ & 0.5 \\
\hline 3 & 6 & 117 & $\mathbf{F}$ & 123 & 123 & $11 \cdot 4$ & 11.6 & 0.9 \\
\hline 4 & 12 & 147 & $\mathbf{F}$ & 71 & 83 & $9 \cdot 7$ & $9 \cdot 5$ & 0.7 \\
\hline 5 & 12 & 150 & F & 71 & 65 & $11 \cdot 1$ & $11 \cdot 1$ & 0.4 \\
\hline 6 & 6 & 128 & $\mathbf{M}$ & 60 & 60 & $8 \cdot 8$ & 8.9 & 0.8 \\
\hline 7 & 10 & 132 & $\mathbf{M}$ & 91 & 85 & $10 \cdot 5$ & $7 \cdot 8$ & 0.7 \\
\hline 8 & 12 & 152 & $\mathrm{~F}$ & 85 & 85 & $10 \cdot 7$ & $10 \cdot 7$ & 0.7 \\
\hline 9 & 12 & 155 & $\mathbf{F}$ & 97 & 98 & $10 \cdot 1$ & $10 \cdot 7$ & 0.9 \\
\hline Mean & & & & 87 & 86 & $10 \cdot 3$ & $10 \cdot 3$ & 0.8 \\
\hline
\end{tabular}

None of the differences between mean baseline measurements was significant. ${ }^{\star}$ Coefficient of variation $=(\mathrm{SD} / \mathrm{mean}) \times 100$, and is the mean of the two study days. $\mathrm{FEV}_{1}=$ forced expiratory volume in one second; $\mathrm{PtcO}_{2}=$ transcutaneous oxygen tension. 
the two study days. Although there was no significant mean difference in prechallenge $\mathrm{PtcO}_{2}$ between the two days for the group, the baseline $\mathrm{PtcO}_{2}$ differed by over $25 \%$ in two of the nine subjects.

No correlation between the baseline $\mathrm{FEV}_{1}$ and $\mathrm{PC}_{20} \mathrm{FEV}_{1}$ or between the baseline $\mathrm{Ptco}_{2}$ and $\mathrm{PC}_{15} \mathrm{Ptco}_{2}$ or $\mathrm{PC}_{10} \mathrm{PtcO}_{2}$ was found. When differences in prechallenge $\mathrm{FEV}_{1}$ and baseline $\mathrm{PtcO}_{2}$ values between the two study days were compared with changes in the corresponding $\mathrm{PC}_{20} \mathrm{FEV}_{1}$ and $\mathrm{PC}_{15} \mathrm{Ptco}_{2}$ or $\mathrm{PC}_{10} \mathrm{PtcO}_{2}$ values, no statistically significant correlation was found.

\section{REPEATABILITY}

The results of the repeated $\mathrm{PC}_{20} \mathrm{FEV}_{1}$, $\mathrm{PC}_{15} \mathrm{PtcO}_{2}$ and $\mathrm{PC}_{10} \mathrm{PtcO}_{2}$ measurements are summarised in table 2 . There was no significant difference in the geometric mean in any of the three provocative indices on the two study days. The figure shows the relation between provocative indices for the two tests.
Results of the $95 \%$ range for subjects based on a single determination of the provocative concentration and the intraclass correlation coefficient are given in table 3. Although $\mathrm{PC}_{20} \mathrm{FEV}_{1}$ was the most reproducible index, repeat tests were within 1.25 doubling concentrations for both $\mathrm{PC}_{20} \mathrm{FEV}_{1}$ and $\mathrm{PC}_{15} \mathrm{Ptco}_{2}$, and within 1.5 doubling concentrations for $\mathrm{PC}_{10} \mathrm{PtcO}_{2}$. The values of the intraclass correlation coefficient-that is the proportion of total variance caused by subject differences as opposed to random measurement error-were acceptable ( $\geq 0.6$ for all three provocative concentration indices)..$^{16}$

By plotting the difference in provocative concentration against the mean provocative concentration for each subject, the repeatability of the provocative indices could be assessed. No systematic variation was found for the differences over the range of the measurement and the $95 \%$ range for a single determination was within 2 SDs-that is the limits of agreement-for all provocative indices.

Table 2 Results of repeated methacholine provocation challenges

\begin{tabular}{|c|c|c|c|c|c|c|}
\hline \multirow{2}{*}{$\begin{array}{l}\text { Patient } \\
\text { No }\end{array}$} & \multicolumn{2}{|c|}{$P C_{20} F E V_{1}(\mathrm{mg} / \mathrm{ml})$} & \multicolumn{2}{|c|}{$\mathrm{PC}_{15} \mathrm{PtcO}_{2}(\mathrm{mg} / \mathrm{ml})$} & \multicolumn{2}{|c|}{$\mathrm{PC}_{10} \mathrm{PtcO}_{2}(\mathrm{mg} / \mathrm{ml})$} \\
\hline & Day 1 & Day 2 & Day 1 & Day 2 & Day 1 & Day 2 \\
\hline $\begin{array}{l}1 \\
2 \\
3 \\
4 \\
5 \\
6 \\
7 \\
8 \\
9\end{array}$ & $\begin{array}{l}2 \cdot 0 \\
0 \cdot 5 \\
5 \cdot 0 \\
0 \cdot 8 \\
1 \cdot 7 \\
5 \cdot 0 \\
2 \cdot 0 \\
5 \cdot 4 \\
4 \cdot 7\end{array}$ & $\begin{array}{r}2.2 \\
0.5 \\
11.8 \\
0.8 \\
1.4 \\
5.0 \\
1.8 \\
6.4 \\
3.3\end{array}$ & $\begin{array}{r}6 \cdot 4 \\
2 \cdot 3 \\
16 \cdot 0 \\
2 \cdot 2 \\
1 \cdot 5 \\
13 \cdot 2 \\
3 \cdot 0 \\
9 \cdot 4 \\
7 \cdot 2\end{array}$ & $\begin{array}{r}3 \cdot 1 \\
3 \cdot 7 \\
13.0 \\
2.3 \\
1.4 \\
12.5 \\
1.3 \\
6.0 \\
4.7\end{array}$ & $\begin{array}{r}3.4 \\
1.4 \\
8.6 \\
1.2 \\
0.9 \\
10.0 \\
1.0 \\
1.5 \\
4.0\end{array}$ & $\begin{array}{l}1.5 \\
2.6 \\
6.4 \\
1.3 \\
1.0 \\
9.2 \\
0.7 \\
0.9 \\
1.4\end{array}$ \\
\hline Geometric mean & $2 \cdot 3$ & $2 \cdot 4$ & $5 \cdot 0$ & 3.9 & $2 \cdot 4$ & 1.9 \\
\hline
\end{tabular}

None of the differences between means was significant. $\mathrm{PC}=$ provocative concentration; $\mathrm{PC}_{20} \mathrm{FEV}_{1}=$ provocative concentration of methacholine required to cause a $20 \%$ reduction in forced expiratory volume in one second; $\mathrm{PtcO}_{2}=$ transcutaneous oxygen tension.

Table 3 Measures of repeatability for the three indices of provocation

\begin{tabular}{lccc}
\hline & $\mathrm{PC}_{20} \mathrm{FEV}$ & $\mathrm{PC}_{15} \mathrm{PtcO}_{2}$ & $\mathrm{PC}_{10} \mathrm{PtcO}_{2}$ \\
\hline Difference between 1st and 2nd test $\left(\log _{10}\right.$ units) (mean (SD)) & -0.023 & $0 \cdot 11$ & $0 \cdot 11$ \\
& $(0 \cdot 15)$ & $(0 \cdot 18)$ & $(0 \cdot 22)$ \\
Within subject SD ( $\log _{10}$ units) & $0 \cdot 11$ & $0 \cdot 13$ & $0 \cdot 16$ \\
$95 \%$ range for a single measurement (doubling concentrations) & 0.80 & 0.96 & $1 \cdot 12$ \\
Intraclass correlation coefficient & 0.78 & 0.86 & 0.78
\end{tabular}

Within subject SD is equal to the SD of the difference between the 1 st and 2 nd tests $/ 2$. The $95 \%$ range for a single measurement $=t_{0.05} \times$ within subject $\mathrm{SD}$, dividing by the log of 2 to convert into doubling concentrations. Intraclass correlation coefficient $=$ between subject variance/total variance. For abbreviations see legend to table 2 .
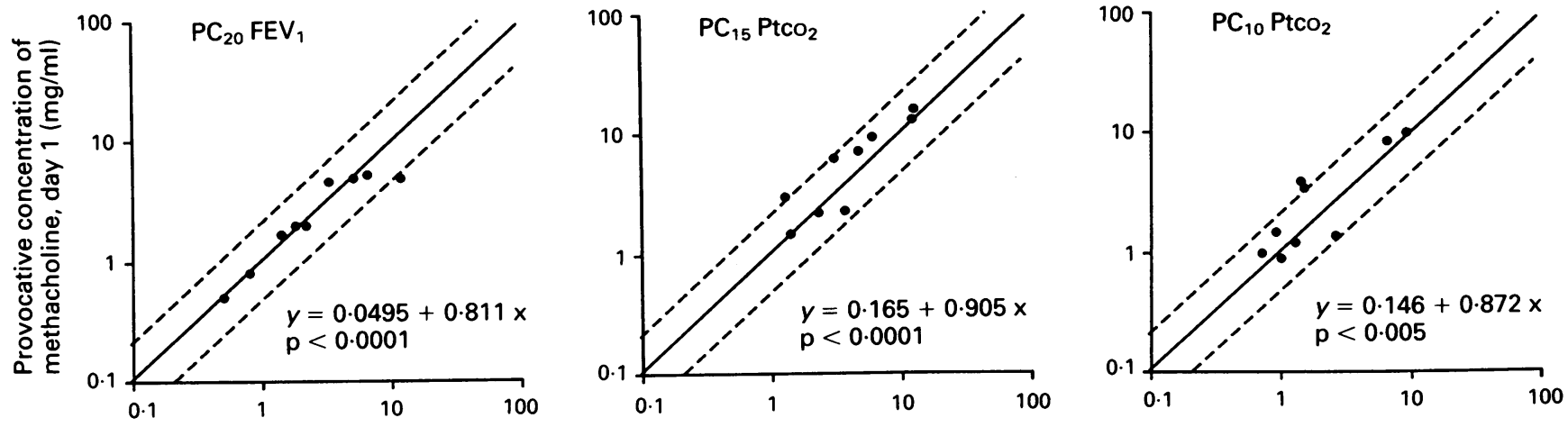

Provocative concentration of methacholine, day $2(\mathrm{mg} / \mathrm{ml})$

Repeatability of $P C_{20} F E V$, (left), $P C_{15} P_{t c O_{2}}$ (middle), and $\mathrm{PC}_{10} \mathrm{PtcO}_{2}$ (right) in nine asthmatic children. The first day is plotted against the second day. The solid lines are the lines of identity and the dotted lines represent \pm 1 doubling concentration difference. For abbreviations see legend to table 2. 


\section{Discussion}

In this study we compared the 24 hour repeatability of methacholine provocation in asthmatic children measured using a conventional lung function technique $\left(\mathrm{FEV}_{1}\right)$ and a newer method that detects indirectly an airway response as a fall in $\mathrm{PtcO}_{2}$. We found that for all subjects the $\mathrm{PC}_{15} \mathrm{PtcO}_{2}$ was within 1.25 doubling concentrations for repeated tests, which was also within the range found when we used $\mathrm{PC}_{20} \mathrm{FEV}_{1}$. The $\mathrm{PC}_{15} \mathrm{Ptco}_{2}$ was only slightly less repeatable than $\mathrm{PC}_{20} \mathrm{FEV}_{1}$ when assessed as the $95 \%$ range of a single determination (table 3). The $\mathrm{PG}_{0} \mathrm{PtcO}_{2}$ was relatively less repeatable than the other indices, although all repeated tests were within 1.5 doubling concentrations. We used the intraclass correlation coefficient as a dimensionless index of repeatability. For a measurement to be useful, it is recommended that it should have an intraclass correlation coefficient of at least $0 \cdot 6 .{ }^{16}$ Both $\mathrm{PC}_{15} \mathrm{PtcO}_{2}$ and $\mathrm{PC}_{10} \mathrm{PtcO}_{2}$ indices satisfied this criterion. The repeatability of the $\mathrm{PC}_{20} \mathrm{FEV}_{1}$ found in this study is similar to that in previous reports. ${ }^{17-19} \mathrm{PC}_{15} \mathrm{PtcO}_{2}$ also showed a similar degree of repeatability.

The repeatability of the $\mathrm{PtcO}_{2}$ method in this study supports the findings of Mochizuki et al, who showed that the shape of dose-response curves were significantly correlated for repeated challenges in sedated and unsedated subjects. ${ }^{28}$ Investigators tend to apply three to four times the mean value of the coefficient of variation for determining a provocative index considered to show a significant change from baseline-that is, a $20 \%$ fall in $\mathrm{FEV}_{1}$ and a $40 \%$ increase in airway resistance. ${ }^{1120}$ In this study we found that the provocative concentration that caused a $10 \%$ fall in $\mathrm{PtcO}_{2}$ was of adequate repeatability but was slightly less repeatable than that required to cause a $15 \%$ fall.

We found that a fall in $\mathrm{FEV}_{1}$ was reflected by an approximately half fold fall in $\mathrm{Ptco}_{2}$ (table 2). Murakami et al reported that a fall of $>20 \%$ in $\mathrm{FEV}_{1}$ was equivalent to a $>10 \%$ fall in $\mathrm{Ptco}_{2}$, findings similar to ours. ${ }^{7}$ In contrast, Eber $e t$ al found an almost equivalent fall in $\mathrm{FEV}$ and $\mathrm{PtcO}_{2}$ after cold air challenge in asthmatic children. ${ }^{5} \mathrm{~A}$ full inspiration causes the $\mathrm{PtcO}_{2}$ to increase transiently. The reduced sensitivity in $\mathrm{PtcO}_{2}$ observed in our study is unlikely, however, to be a result of this effect since the maximal fall in $\mathrm{Ptco}_{2}$ was recorded at least four minutes after the previous $\mathrm{FEV}_{1}$ had been performed. Another possibility is that the maximal ventilatory manoeuvres involved in the measurement of the response itself may have modified the relation of changes in $\mathrm{Ptco}_{2}$ to a decrease in lung function. This could be the reason for the large difference between $\mathrm{PC}_{15}$ $\mathrm{Ptco}_{2}$ and $\mathrm{PC}_{10} \mathrm{Ptco}_{2}$ in some of the subjects. In this study all subjects had identical challenges on the two days and the numbers of baseline measurements and $\mathrm{FEV}_{1}$ manoeuvres undertaken after challenge were also strictly controlled. Thus, although respiratory manoeuvres included as part of the challenge protocol may have modified the magnitude of $\mathrm{PtcO}_{2}$ change and may explain some of the small differences between the different studies, the repeatability of the method is unlikely to have been affected.

Repeatability is important for the standardisation of inhalation provocation tests. Our bronchial challenge procedure was modified in several ways from that of Cockcroft et al ${ }^{11}$ to make it more suitable for uncooperative preschool children. ${ }^{22}$ Firstly, the nebulisation period was reduced to one minute instead of the usual two minutes. Secondly, the incremental concentrations of inhaled methacholine were increased from doubling to quadrupling steps until a $1 \mathrm{kPa}$ fall in $\mathrm{PtcO}_{2}$ had been obtained, after which concentrations were administered in doubling steps. Reduction of the inhalation period to one minute still allowed a similar level of repeatability to that found by other investigators, using a standardised full challenge protocol. ${ }^{17-19}$ By using quadrupling concentrations instead of doubling concentrations, the length of time required for the challenge protocol can be almost halved, without any loss in the precision of the test. A typical full length challenge requiring four concentrations of methacholine would take approximately 19 minutes to complete after baseline measurements of lung function.

At present there are no lung function techniques that are suitable for the measurement of bronchial responsiveness in children aged 1-5 years. Although the forced oscillation technique has been recommended for the measurement of lung function in preschool children ${ }^{21}$ as it requires only passive cooperation, it is often very difficult to obtain consistent repeated measurements if the child is not sedated. In contrast, we have found the measurement of $\mathrm{PtcO}_{2}$ to assess the response to methacholine easy to use in preschool children. ${ }^{22}$ It was difficult, however, to persuade such young children to repeat the test within a 24 hour period. The finding that the $\mathrm{PtcO}_{2}$ technique is repeatable in older children further demonstrates the reliability of the method.

We are grateful to the National Asthma Campaign for their continued support.

1 Wilson NM, Phagoo SB, Silverman M. Use of transcutaneous oxygen tension, arterial oxygen saturation, and respiratory resistance to assess the response to inhaled methacholine in asthmatic children and normal adults. Thorax 1991;46:433-7.

2 Mochizuki H, Mitsuhashi M, Tokuyama K, Tajima K, Morikawa A, Kuroume T. A new method of estimating bronchial hyperresponsiveness in younger children. Ann Allergy 1985;55:162-6.

3 Bjure J, Engstrom I, Holmgren D, Sten G. Transcutaneous $\mathrm{PO}_{2}$ monitoring in histamine provocation test. Pediatr Pulmonol 1988;4:106.

4 Gray B, Barnes N, Nyeko C, Marquis A. Changes in transcutaneous oxygen and carbon dioxide in response to histamine bronchial challenge. Thorax 1986;41:246.

5 Eber E, Varga EM, Zach MS. Cold air challenge of airway reactivity in children: a correlation of transcutaneously measured oxygen tension and conventional lung functions. Pediatr Pulmonol 1991;10:273-7.

6 Prendiville A, Maxwell DL, Rose A, Silverman M. Histamine-induced airway obstruction in infancy: changes in oxygenation. Pediatr Pulmonol 1988;4:164-8.

7 Murakami G, Igarashi T, Adachi Y, Matsuno M, Sawai M, Yoshizumi A, et al. Measurement of bronchial hyperreactivity in infants and preschool children using a new method. Ann Allergy 1990;64:383-7.

8 Mochizuki H, Mitsuhashi M, Tokuyama K, Tajima K, 
Morikawa A, Kuroume T. Bronchial hyperresponsiveness in younger children with asthma. Ann Allergy 1988;60: 103-6.

9 Yan K, Salome C, Woolcock AJ. Rapid method for measurement of bronchial responsiveness. Thorax 1983 38:760-5.

10 Chatham M, Bleecker ER, Norman P, Smith PL, Mason P. A screening test for airways reactivity-an abbreviated methacholine inhalation challenge. Chest 1982:82:15-8.

11 Cockcroft DW, Killian DN, Mellon JJA, Hargreave FE. Bronchial reactivity to inhaled histamine: a method and clinical survey. Clin Allergy 1977;7:235-43.

12 Polgar G, Promadhat V. Pulmonary function testing in children: techniques and standards. Philadelphia, London, Toronto: WB Saunders Co, 1971.

13 Altman DG, Bland JM. Measurement in medicine: the analysis of methods comparison studies. The Statistician 1983;32:307-17.

14 Fleiss JL. The design and analysis of clinical experiments. New York. John Wiley \& Sons, 1986:1-14.

15 Bland MJ, Altman DG. Statistical methods for assessing agreement between two methods of clinical measurement. Lancet 1986; i:307-10.

16 Chinn S. Repeatability and method comparison. Thorax $1991 ; 46: 454-6$.
17 Cockcroft DW, Berscheid BA, Murdock KY. Measurement of responsiveness to inhaled histamine using FEV : com parison of $\mathrm{PC}_{20}$ and threshold. Thorax 1983;38:523-6.

18 Ryan G, Dolovich MB, Roberts RS, Frith PA, Juniper EF, Hargreave FE, et al. Standardization of inhalation provocation tests: two techniques of aerosol generation and inhalation compared. Am Rev Respir Dis 1981;123. 195-9.

19 Juniper EF, Frith PA, Dunnett C, Cockcroft DW, Hargreave FE. Reproducibility and comparison of responses to inhaled histamine and methacholine. Thorax ponses to inhaled

20 SEPCR Working Group 'Bronchial Hyperreactivity'. Eds Eiser NM, Kerrebijn KF, Quanjer PH. Guidelines fo standardization of bronchial challenges with (non-specific) bronchoconstricting agents. Bull Eur Physiopathol Respir 1983;19:495-514

21 Duiverman EJ, Neijens HJ, Van Strik R, Van Der Snee-Van Smaalen M, Kerrebijn KF. Bronchial responsiveness in asthmatic children aged 3 to 8 years measured by forced pseudo-random noise oscillometry. Bull Eur Physiopathol Respir 1986;22:27-34.

22 Wilson NM, Phagoo SB, Silverman M. Atopy, bronchia responsiveness and symptoms in 3 year old wheezy children. Arch Dis Child 1992;67:491-5.

\section{Adventitia}

\section{Every dogma has its day}

When I went to Baltimore, Maryland, in 1958 , to supplement my meagre salary I worked in the Baltimore city health department tuberculosis clinics. At that time, depending on their colour, those who developed tuberculosis were confined to one or other of two monolithic goals. If they were lucky they would emerge after some mutilative surgical procedure two or three years later. Refusal to undergo treatment resulted in a court order and almost certain confinement. When the owner of the premier Chinese restaurant in Baltimore developed tuberculosis one of the more important issues before the city council was to decide whether he would be admitted to the black or the white sanatorium. As a successful entrepreneur, he received special dispensation and was admitted to the white facility.

About that time the British and Indian Medical Research Councils published the results of the Madras study showing that tuberculosis could be treated as effectively at home as in hospital, and that once chemotherapy had been started, and despite persistently positive sputum, the patient lost his infectiousness within a few days. The study was dismissed with scorn by most of the tuberculosis establishment in the United States. It was about that time that I had the good fortune to come into contact with $\mathrm{Dr}$ Richard Riley, who at that time was head of the department of environmental medicine at the Johns Hopkins Medical School. His name was known to me as the originator of the method for measuring the diffusing capacity for oxygen and for his seminal work on ventilation-perfusion relationships while he was at Bellevue Hospital. A self effacing and modest man, Dick Riley, in the opinion of many, had been the major driving force in the laboratory of Cournand and Richards. He had a tremendous and justified reputation as a respiratory physiologist, but few at that time knew that he had been working for several years with the late Professor Wells on the infectiousness of tuberculosis and had been conducting a series of most ingenious experiments at Loch Raven Veterans Administration Hospital. The ventilation system there had been modified so that air could be extracted from a series of single wards in which were housed patients with tuberculosis, some of whom were undergoing treatment while others had not yet started treatment. In a few rooms patients with acquired drug resistance were housed. The extracted air was carried by a series of vents to several chambers containing guinea pigs and then vented to the outside. These studies showed irrevocably the lack of infectiousness of patients once they had started chemotherapy, the sterilising effect of ultraviolet light on droplet nuclei containing tubercle bacilli, and much else besides. Few contemporary physicians realised the contribution Dick Riley made to the termination of the gaol sentences that were part and parcel of the treatment in Maryland and elsewhere in the United States, and still fewer were aware that he himself had been successfully treated for tuberculosis.

WKC MORGAN 